American Journal of Environmental Sciences 6 (1): 45-49, 2010

ISSN 1553-345X

(C) 2010 Science Publications

\title{
Part I: Removing of Zn(II) from Polluted Water: Determination of Precipitation Limit Of Zn(II) Ion With 2-Hydroxy-1,2,3-Propanetricarboxylic Acid
}

\author{
${ }^{1}$ Fatmir Faiku, ${ }^{1}$ Haxhere Faiku, ${ }^{1}$ Arben Haziri, ${ }^{1}$ Sevdije Govori, \\ ${ }^{2}$ Murtezan Ismaili and ${ }^{1}$ Albert Maxhuni \\ ${ }^{1}$ Department of Chemistry, Faculty of Natural Sciences, University of Prishtina, \\ Mother Tereza Street 5, 10000 Prishtina, Republic of Kosova \\ ${ }^{2}$ Institute for Environment and Health, South East European University \\ Ilindenska b.b., 1200 Tetovo, Republic of Macedonia
}

\begin{abstract}
Problem statement: The goal of this research was to investigate the condition for removing of $\mathrm{Zn}$ cation from water, through precipitation method with 2-hydroxy-1,2,3-propanetricarboxylic acid as ligand. Approach: In this study we examined the precipitation of $\mathrm{Zn}(\mathrm{II})$ ion in water solutions of $\mathrm{ZnSO}_{4} \times 7 \mathrm{H}_{2} \mathrm{O}\left(1 \times 10^{-2}\right.$ and $\left.5 \times 10^{-3} \mathrm{~mol} \mathrm{~L}^{-1}\right)$ with 2-hydroxy-1,2,3-propanetricarboxylic acid $\left(1 \times 10^{-1}\right.$ $1 \times 10^{-3} \mathrm{~mol} \mathrm{~L}^{-1}$ ) in constant ionic strength of $0.6 \mathrm{~mol} \mathrm{~L}^{-1} \mathrm{NaCl}$. We have determined the concentration region at which $\mathrm{Zn}$ (II) start to precipitate. Results: From precipitation diagrams of zinc with 2hydroxy-1,2,3-propanetricarboxylic acid, in ionic force $0.6 \mathrm{~mol} \mathrm{~L}^{-1} \mathrm{NaCl}$, we have found that during decreasing the concentration of 2-hydroxy-1,2,3-propanetricarboxylic acid, in case of constant concentration of $\mathrm{Zn}(\mathrm{II})$, the limit of precipitation is shifted to lower values of $\mathrm{pH}$. The solid phase is analyzed by IR spectroscopy. Conclusion: From the IR spectroscopic analysis we can conclude that $\mathrm{Zn}$ (II) ion can precipitate with 2-hydroxy-1,2,3-propanetricarboxylic acid.
\end{abstract}

Key words: Environment, precipitation limit, $\mathrm{Zn}(\mathrm{II})$ ion, ligands, 2-hydroxy-1,2,3propanetricarboxylic acid, IR spectroscopy

\section{INTRODUCTION}

Human activities can cause water pollution or can pollute river sediments (Montgomery, 1985). Components from organic or inorganic origin, within time they can sediment in lower part of river. The sediment from river contains heavy toxic metals, organic or inorganic components (Halamic et al., 2001). Water from river can contain ions $(\mathrm{Cu}, \mathrm{Cd}, \mathrm{Zn}, \mathrm{Pb}, \mathrm{Al}$ and $\mathrm{Hg}$ ), depends on pollution, which are very toxic for water organisms. If these ions bind with different ligands (organic molecules), the metal toxicity will reduce. Natural water contains a lot of molecules and ions with organic and inorganic origin. Cations in natural water can be present as complex, but anions can be from human activities (phosphates and dicarboksilik acids), (Hammond, 1971) or can be present from natural humic acids and aminoacids (Flaig and Beutelspacher, 1975; Schnitzer and Khan, 1978). Investigation of the interactions between metals and ligands, is very important for Environmental chemistry.

Oceans and seas water contain metals, also zinc and other helate ligands in normal quantity but sometimes depends on pollution they can contain high level of these metals and ligands. We can find complexes which are not stable with different inorganic ligands, as example chloride ions, or complexes, which are stable and these are formed from metals and helate ligands from organic maters or formed from polluted water (Ibanez et al., 2007).

Toxic metals as zinc are considered as non toxic when it is complexes with helate ligands. Water organisms (fish's) can eat these complexes, but it is not believed that these kinds of compounds can entry to the nutritive chain. But this should investigate very carefully in each case (Ibanez et al., 2007).

The Aim of this work was to investigate the condition for removing of $\mathrm{Zn}$ cation from water, through precipitation method with 2-hydroxy-1,2,3propanetricarboxylic acid as ligand.

\section{MATERIALS AND METHODS}

In this study we used $\mathrm{ZnSO}_{4} \times 7 \mathrm{H}_{2} \mathrm{O}$, 2-hydroxy1,2,3-propanetricarboxylic acid as a ligand, sodium hydroxide and sodium chloride. For this investigation

Corresponding Author: Fatmir Faiku, Department of Chemistry, Faculty of Natural Sciences, University of Prishtina, Mother Tereza Street 5, 10000 Prishtina, Republic of Kosova 
we have prepared some concentrated solutions which are stored on glass bottles in room temperature. Diluted solution we have prepared fresh for each series of precipitated systems. The precipitated systems are prepared using methods from Tezak et al. (1951).

Precipitated system, $\mathrm{ZnSO}_{4} \times 7 \mathrm{H}_{2} \mathrm{O}$ with 2hydroxy-1,2,3-propanetricarboxylic acid, is investigated in the long region of concentration with ionic force of $\mathrm{NaCl} 0.6 \mathrm{~mol} \mathrm{~L}^{-1}$.

As example, one series it's prepared in this way:

- The solution was added in two line of test-tube. In the first line of test tubes is added the solution of $\mathrm{ZnSO}_{4} \times 7 \mathrm{H}_{2} \mathrm{O}$ with known concentration (as example $1 \times 10^{-1} \mathrm{~mol} \mathrm{~L}^{-1}$ ). In second line of test tube we added the 2-hydroxy-1,2,3propanetricarboxylic acid solution, also with known concentration (as example $1 \mathrm{~mol} \mathrm{~L}^{-1}$ ). The second line of test tube we added $\mathrm{NaCl}$ in that way that ionic force to be $0.6 \mathrm{~mol} \mathrm{~L}^{-1}$. After that we added the solution of $\mathrm{NaOH}$ to increase the $\mathrm{pH}$ value. The total volume in each test tube should be $10 \mathrm{~mL}$. The differences till $10 \mathrm{~mL}$, we have fill with distillate water

- Solution from the first line tubes was added to the solution of second test tube (7 times per $20 \mathrm{sec}$ ). All the concentration is calculated on the total volume after mixing, which means at $10 \mathrm{~mL}$. The systems after mixed are stored on thermostat for $24 \mathrm{~h}$ in $25^{\circ} \mathrm{C}$. To determine the precipitated diagrams, when the concentration of $\mathrm{Zn}$ ions stays unchanged, we have to change the concentration of 2-hydroxy-1,2,3-propanetricarboxylic acid. For that we used three deferent concentration of 2hydroxy-1,2,3-propanetricarboxylic acid for one concentration of $\mathrm{Zn}(\mathrm{II})$ ion. We used concentration of 2-hydroxy-1,2,3propanetricarboxylic acid $1 \times 10^{-1}, 1 \times 10^{-2}$ and $1 \times 10^{-3} \mathrm{~mol} \mathrm{~L}^{-1}$ for each concentration of $\mathrm{Zn}(\mathrm{II})$. For zinc (II) ion we used two concentration $1 \times 10^{-2}$ and $5 \times 10^{-3} \mathrm{~mol} \mathrm{~L}^{-1}$. At all of these systems we added solution of $\mathrm{NaCl}$ in that way that ionic force to be $0.6 \mathrm{~mol} \mathrm{~L}^{-1}$. Also we added the $\mathrm{NaOH}$ to change the $\mathrm{pH}$ values. Precipitated systems are monitories after $24 \mathrm{~h}$. It is determinate the concentration which cause the difference between clear solution and precipitation. Then it is measured the $\mathrm{pH}$ value on the top of precipitate with pH meter, "Metrohm"

- Some precipitates are prepared in large quantity for quantity analysis. Systems have stored in thermostat for $24 \mathrm{~h}$ in the temperature of $25^{\circ} \mathrm{C}$ and then the $\mathrm{pH}$ value is measured on the top of precipitate. These systems are filtered (we used filtered paper with blue line for filtration) and are dried on the air. We used the IR spectra to characterize and to find the presence of organic components to precipitate. To record IR spectra we used spectrophotometer, "SHIMADZU 8400 S" with potassium bromide technique

\section{RESULTS}

Precipitation of zinc(II) with 2-hydroxy-1,2,3propanetricarboxylic acid was investigated to concentration of zinc $1 \times 10^{-2}$ and $5 \times 10^{-3} \mathrm{~mol} \mathrm{~L}^{-1}$ with different concentration of 2-hydroxy-1,2,3propanetricarboxylic acid $\left(1 \times 10^{-1}, \quad 1 \times 10^{-2}\right.$ and $\left.1 \times 10^{-3} \mathrm{~mol} \mathrm{~L}^{-1}\right)$. We have added the solution of $\mathrm{NaCl}$ because we want that general ionic force to be $0.6 \mathrm{~mol} \mathrm{~L}^{-1}$. In this mixture we added the $\mathrm{NaOH}$ solution in that way that $\mathrm{pH}$ increase continually and from here to find at which $\mathrm{pH}$ values the $\mathrm{Zn}(\mathrm{II})$ ion will precipitate.

\section{DISCUSSION}

From the precipitation diagram of $\mathrm{Zn}(\mathrm{II})$ with 2hydroxy-1,2,3-propanetricarboxylic acid we can see, that when concentration of zinc is $1 \times 10^{-2} \mathrm{~mol} \mathrm{~L}^{-1}$ and concentration of 2-hydroxy-1,2,3-propanetricarboxylic acid $1 \times 10^{-1} \mathrm{~mol} \mathrm{~L}^{-1}$ (Fig. 1) we have not the precipitate,

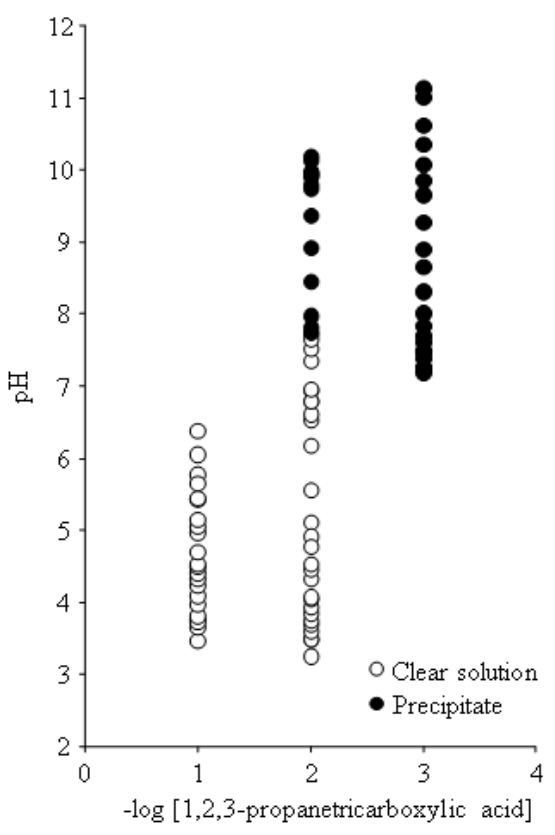

Fig. 1: Precipitate diagram of $\mathrm{Zn}(\mathrm{II})$ in concentration $1 \times 10^{-2} \mathrm{~mol} \mathrm{~L}^{-1}$ 
but the precipitation start when the concentration of 2 hydroxy-1,2,3-propanetricarboxylic acid is $1 \times 10^{-2}$ and $1 \times 10^{-3} \mathrm{~mol} \mathrm{~L}^{-1}$ at the value of $\mathrm{pH}=7.81$ and 7.19, respectively. At $\mathrm{pH}=10.27$ the precipitate start when the concentration of $\mathrm{Zn}$ is $5 \times 10^{-3} \mathrm{~mol} \mathrm{~L}^{-1}$ and concentration of 2-hydroxy-1,2,3-propanetricarboxylic acid is $1 \times 10^{-1} \mathrm{~mol} \mathrm{~L}^{-1}$ (Fig. 2), but when concentration of 2-hydroxy-1,2,3-propanetricarboxylic acid is $1 \times 10^{-2} \mathrm{~mol} \mathrm{~L}^{-1}$, precipitate start at $\mathrm{pH}=10.03$. When the concentration of 2-hydroxy-1,2,3propanetricarboxylic acid is $1 \times 10^{-3} \mathrm{~mol} \mathrm{~L}^{-1}$ precipitate start at $\mathrm{pH}=6.96$.

We have found that diagrams have not changed after a long stored and for that the time of $24 \mathrm{~h}$ was approved as time of achieved the equilibrium. To analyze the precipitate, some of test tubes are filtered and are dried in the room temperature. These precipitate are characterized with IR spectra (Fig. 4 and 5).

We have obtained also the IR spectra of 1,2,3-propanetricarboxylic acid (Fig. 3). Comparing the IR specters, we can conclude that we have interaction between $\mathrm{Zn}$ and 1,2,3-propanetricarboxylic acid.

To the 1,2,3-propanetricarboxylic acid IR spectra (Fig. 3) we see the peaks at $1710 \mathrm{~cm}^{-1}$ which characterize the carboxyl group. At solid phase this peak is shifted at lower values, $1600 \mathrm{~cm}^{-1}$ (Fig. 4 and 5). This tells us for the interaction of $\mathrm{Zn}$ with 1,2,3- propanetricarboxylic acid. The breit peak at $1100 \mathrm{~cm}^{-1}$ is characteristic for the interaction of $\mathrm{Zn}-\mathrm{OH}$.

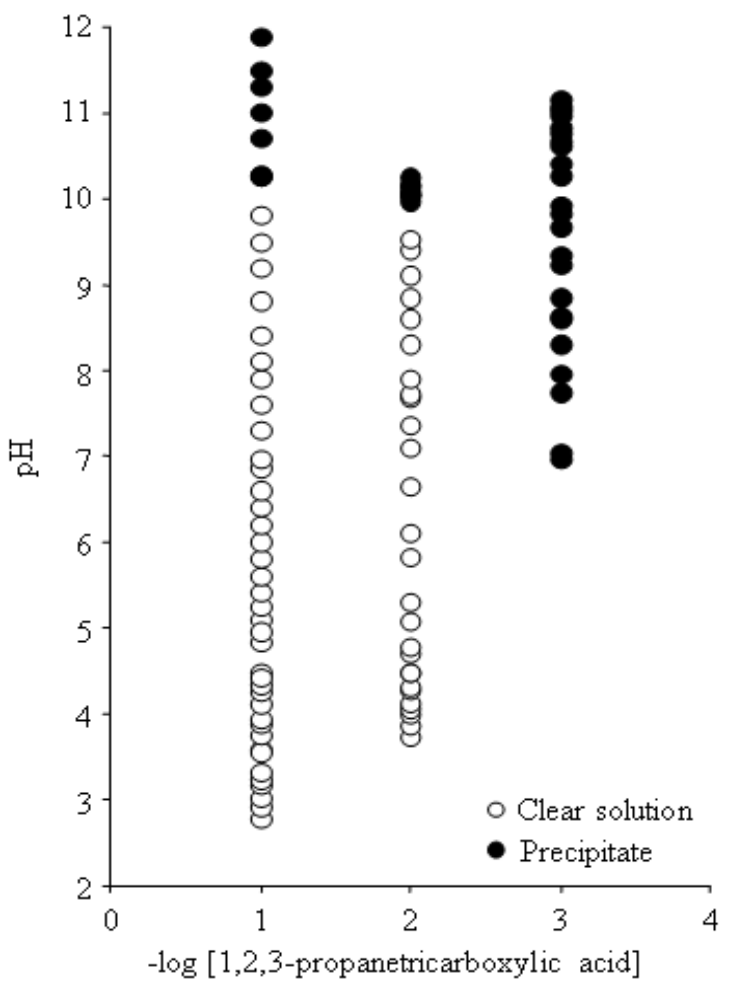

Fig. 2: Precipitate diagram of $\mathrm{Zn}(\mathrm{II})$ in concentration $5 \times 10^{-3} \mathrm{~mol} \mathrm{~L}^{-1}$

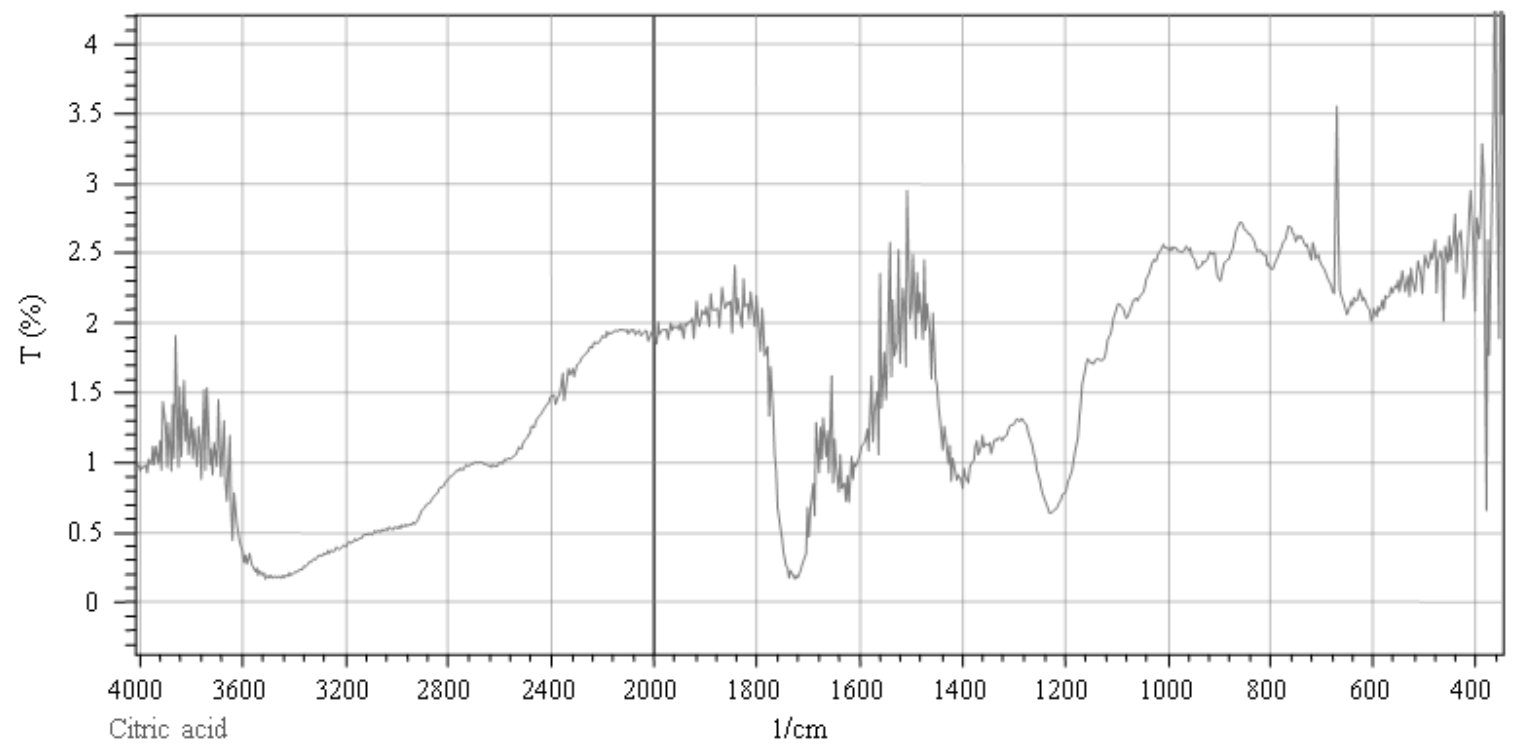

Fig. 3: IR spectra of 1,2,3-propanetricarboxylic acid 
Am. J. Environ. Sci., 6 (1): 45-49, 2010

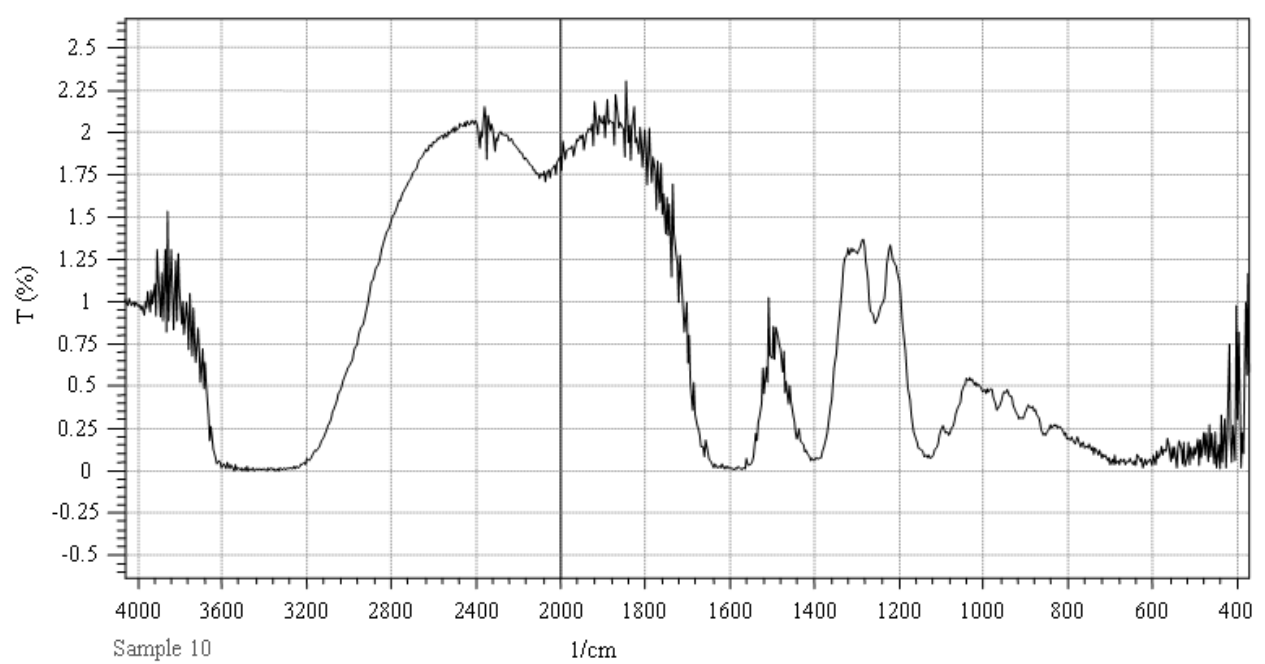

Fig. 4: IR spectra of precipitate which is formed after interaction of $\mathrm{Zn}$ (II) with 1,2,3propanetricarboxylic acid $\left(\mathrm{c}\left(\mathrm{ZnSO}_{4} \cdot 7 \mathrm{H}_{2} \mathrm{O}\right)=5 \times 10^{-3} \mathrm{~mol} \mathrm{~L}^{-1}, \mathrm{c}(1,2,3\right.$-propanetricarboxylic acid $)=1 \times 10^{-3} \mathrm{~mol} \mathrm{~L}^{-1}, \mathrm{pH}=9.46$ )

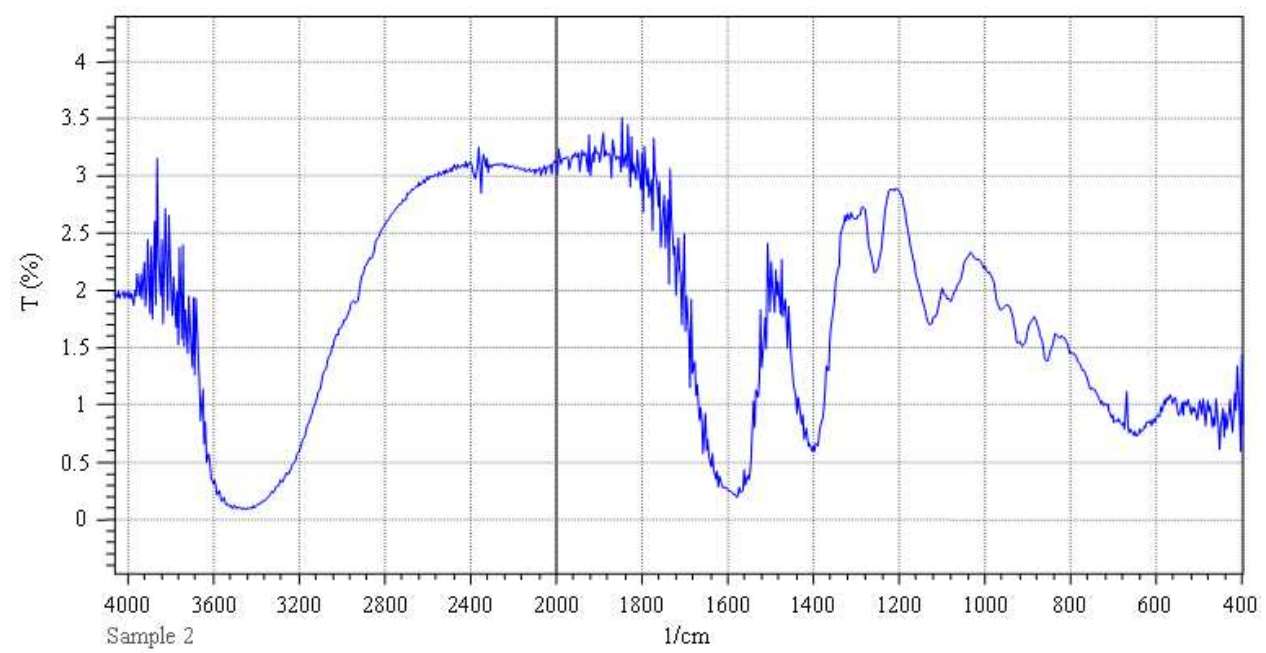

Fig. 5: IR spectra of precipitate which is formed after interaction of $\mathrm{Zn}$ (II) with 1,2,3propanetricarboxylic acid $\left(\mathrm{c}\left(\mathrm{ZnSO}_{4} \cdot 7 \mathrm{H}_{2} \mathrm{O}\right)=1 \times 10^{-2} \mathrm{~mol} \mathrm{~L}^{-1}, \mathrm{c}(1,2,3\right.$-propanetricarboxylic acid) $\left.=1 \times 10^{-2} \mathrm{~mol} \mathrm{~L}^{-1}, \mathrm{pH}=6.72\right)$

\section{CONCLUSION}

To investigate the interaction between ligands and metals, which can be present in natural water, is very important for Environment. For that we have analyzed the precipitation diagrams of $\mathrm{Zn}(\mathrm{II})$ ion with 2hydroxy-1,2,3-propanetricarboxylic acid. From our results we can conclude:

- Also from precipitation diagrams of zinc with 2hydroxy-1,2,3-propanetricarboxylic acid at ionic force of $0.6 \mathrm{~mol} \mathrm{~L}^{-1} \mathrm{NaCl}$, we can see that when the concentration of 2-hydroxy-1,2,3propanetricarboxylic acid decrease, in case of constant concentration of zinc, the limit of precipitation will shift at lower values of $\mathrm{pH}$

- Solid precipitates are analyzed by IR spectrophotometer and the IR spectra which we have obtained are compared with IR spectra of 2hydroxy-1,2,3-propanetricarboxylic acid. From the IR spectra of solid phase we can conclude that zinc 


\begin{abstract}
can react with 2-hydroxy-1,2,3-
propanetricarboxylic acid

\section{ACKNOWLEDGMENT}

The researchers acknowledge the financial support received from the University of Prishtina, Kosova.
\end{abstract}

\section{REFERENCES}

Flaig, W. and H. Beutelspacher, 1975. Chemical Composition and Physical Organic Components. In: Soil Components Organic Components, Gieseking, J.E. (Ed.)., Vol. 1, Springer-Verlag, New York, pp: 524.

Halamic, J., Z. Peh, D. Bukovec, S. Miko, L. Galovic, 2001. A factor model of the relationship between stream sediment geochemistry and adjacent drainage basin lithology, Medvednica Mt. Geol. Croat., 54: 37-51. http;?//hrcak.srce.hr/index.php?show=toc\&id_broj $=396$.
Hammond, H., 1971. Phospate replacements: Problems with the washday miracle. Science, 172: 361-369. DOI: $10.1126 /$ science.172.3981.361

Ibanez, J., M. Hernandez-Esparza, C. Doria-serrano, A. Fregoso-Infante and M. Singh, 2007. Environmental Chemistry. 1st Edn., Springer Verlag, New York, ISBN: 0387494928, pp: 238.

Montgomery, J., 1985. Water Treatment, Principles and Design. 2nd Edn., John Willey and Sons, New Jersey, ISBN: 0471043842, pp: 675.

Schnitzer, M. and S.H. Khan, 1978. Soil Organic Matter. Vol. 8, Elsevier Science Publishing Company Inc., New York, ISBN: 0444416102, pp: 319.

Tezak, B., E. Matijevic and K. Schulz, 1951. Coagulation of hydrophobic sols in Statu Nascendi. I. Determination of coagulation values. J. Phys. Colloid Chem., 55: 1557-1567. DOI: $10.1021 / \mathrm{j} 150492 \mathrm{a} 016$ 